\title{
Becoming partners: algunas consideraciones sobre el carácter constructivo de la identidad del consumidor
}

\author{
Felip Vidal AULADELL ${ }^{1}$ \\ EASD Vic
}

Recibido: $27 / 05 / 2014$

Aceptado: 22/01/2015

\section{Resumen}

Este artículo explora el papel que ejercen en el consumidor los elementos emocionales y experienciales que es frecuente encontrar en la actividad publicitaria actual. Se considera cómo, para que la experiencia de consumo sea realmente significativa y para que el consumidor devenga partner de la marca mediante la adhesión experiencial a su imaginario, se requiere que aquél lleve a cabo una actividad proyectiva en la tarea de construir su propia identidad concebida como un proyecto autoconstituyente. Para ello, se ahonda en la función que desempeña la imaginación en la producción de emociones vinculadas al consumo.

Palabras clave: publicidad, experiencia, imaginación, Eva Illouz, J.P. Sartre.

\section{Becoming partners: \\ some considerations on the constructive nature of the consumer's identity}

\begin{abstract}
This article examines the role played by the emotional and experiential elements that are commonly found in modern advertising in the consumer. It considers how in order for the experience of consumption to be truly significant and for the consumer to become a partner of the brand by experiential adhesion to their imagery, they must undertake a projective activity within the task of constructing their own identity, conceived as a self-constituting project. To that end, the article considers the role of imagination in the production of consumption-related emotions.
\end{abstract}

Keywords: advertising, experience, imagination, Eva Illouz, J.P. Sartre.

${ }^{1}$ Doctor en el Ciencias de la Información por la Universidad Complutense de Madrid (UCM). Licenciado en Derecho (UdG) y en Filosofía (UNED). Diploma de Estudios Avanzados (DEA) en el Departamento de Historia de la Filosofía, Estética y Filosofía de la Cultura de la Universidad de Barcelona (UB). Docente en la Escuela de Arte y Superior de Diseño (EASD) de Vic (Barcelona). E.mail: felipvidal@eartvic.net. 


\section{Planteamiento y objetivos}

La identidad viene siendo, desde la década de los 60 del pasado siglo, como señala Hobsbawm $^{2}$, una importante categoría de debate. El primer foco se halló en los EEUU, país construido a partir de diferentes etnias y en el que los movimientos feminista y gay lésbico surgieron con fuerza, liderando el planteamiento de estas controversias. La cuestión de la identidad sigue centrando actualmente el interés de numerosos teóricos, aunque las motivaciones iniciales han ido cambiando con el tiempo, pasando a destacar aquellas relacionadas no sólo con una perspectiva individual sino también colectiva ${ }^{3}$, adquiriendo mayor protagonismo las relacionadas con la globalización ${ }^{4}$.

Además, por otra parte, el llamado "giro lingüístico" produjo un importante cambio en la manera de abordar esta cuestión al poner el énfasis no sólo en el origen discursivo de las identidades sino también en su origen narrativo. En este sentido, las aportaciones de Ricoeur ${ }^{5}$ y Taylor ${ }^{6}$ dieron lugar a un nuevo modo de concebir la identidad como producción social inmersa en procesos simbólicos de significación a través de las narrativas en las que el sujeto participa.

Este creciente interés por la cuestión de la identidad puede ser interpretado, como señala Douglas Kellner, como un «reflejo de una ansiedad general» que adopta, para nuestro presente en ocasiones rotulado como "posmoderno" , unos tonos acuciantes y que, de algún modo, ya habían sido anticipados por $\operatorname{Toffler}^{8}$ hace varias décadas y que podrían relacionarse con fenómenos tal vez más actuales derivados de "la intensificación del pensamiento horizontal"?.

2 Hobsbawm, E. (1996): “Identity politics and the left", New Left Review, n²17, 38-47.

3 Benedict Anderson, en Comunidades imaginadas, trata de conceptualizar la identidad nacional y señala que las naciones son más que simples entidades políticas y geográficas. Son identidades no imaginarias sino imaginadas. Una nación, en este sentido, es "una comunidad polítíca imaginada como inherentemente ilimitada y soberana" (ANDERSON, B. (1993): Comunidades imaginadas. Reflexiones sobre el origen y la difusión del nacionalismo, México, FCE, 23). Siendo ésta imaginada "porque aun los miembros de la nación más pequeña no conocerán jamás a la mayoría de sus compatriotas, no los verán ni oirán siquiera hablar de ellos, pero en la mente de cada uno vive la imagen de su comunión" (Ibíd., 23). Basta constatar, por el momento, la importancia que se atribuye al papel de la imaginación en la construcción de las identidades.

${ }^{4}$ Para Zygmunt Bauman, por ejemplo, "las guerras de la identificación no son contrarias a la tendencia globalizadora ni se interponen en el camino: son un vástago legítimo y un compañero natural de la globalización y, lejos de detenerla, le engrasan las ruedas" (BAUMAN, Z. (2001): La sociedad individualizada, Madrid, Cátedra, 175). Del mismo autor resulta interesante BAUMAN, Z. (2005): Identidad, Madrid, Losada.

5 Ricoeur, P. (1996): Si mismo como otro, Madrid, s.XXI.

6 TAYlor, Ch. (2006): Fuentes del yo, Barcelona, Paidós.

7 Eagleton, T. (1997): Las ilusiones del posmodernismo, Buenos Aires, Paidós. Un análisis conciso sobre la cuestión de la identidad en la postmodernidad puede encontrarse asimismo en STOREY, J. (1999): Cultural Consumption and Everyday Life, London, Arnold, 128 - 148.

8 Toffler, A. (1992): El "shock" del futuro, Barcelona, Plaza\&Janés.

9 Bermejo, J. (2008): "El receptor publicitario del siglo XXI en el marco de la interactividad: entre el consumer y el prosumer", en PACHECo RuEDA, M. (coord.), La publicidad en el contexto digital, Sevilla- Salamanca-Zamora, Comunicación Social Ediciones y Publicaciones, 49-78. 
Así, se suele considerar que, en las sociedades tradicionales, la identidad era más bien fija, sólida, estable y no sujeta a debate, es decir, no problemática ni teórica ni personalmente, en la actualidad ésta ha devenido "more mobile, multiple, personal, self-reflexive, and subject to change and innovation" ${ }^{10}$. Mientras que, como afirma Hall, en nuestra sociedad, donde las identidades son cada vez más fragmentadas y fracturadas, ésta es "never singular but multiplicity constructed across different, often intersecting and antagonistic, discourses, practices and positions" 11 .

Es comprensible, con todo ello, la presencia de aquella citada "ansiedad general" que aparece como el resultado de unos cambios sociales y del paso a sociedades de estructuras más flexibles que ha favorecido una concepción de la identidad como algo no fijado definitivamente sino en perpetuo proceso de formación, de modo que se precisa que el individuo tome parte activa en una tarea de completud sin término.

En la situación actual, además, los medios de comunicación promueven comercialmente y contribuyen a reforzar, para explotarla posteriormente, la conciencia de que vivimos en un entorno completamente inestable. Así, apunta Bauman:

\begin{abstract}
El mensaje que actualmente transmiten con gran poder de persuasión los medios de comunicación culturales más ubicuamente eficaces [...] es un mensaje sobre la indeterminación y ductilidad esenciales del mundo [...] En este mundo, los lazos toman la apariencia de encuentros consecutivos; las identidades, de máscaras que se van usando sucesivamente; la biografía, de una serie de episodios cuya única importancia perdurable reside en su recuerdo igualmente efímero. [...]. La apuesta reina ahora allí donde antes se buscaba la certidumbre, mientras que la asunción de riesgos sustituye a la persecución obstinada de objetivos. Y, por consiguiente, no existen apenas cosas en el mundo que puedan considerarse sólidas y fiables, nada que recuerde a una lona resistente en la que uno podría tejer el propio itinerario de vida ${ }^{12}$.
\end{abstract}

Todo ello conlleva que el yo pueda considerarse como "un espacio 'flotante', sin fijación ni referencia, una disponibilidad pura, adaptada a la aceleración de las combinaciones"13. Y, en este contexto, la pregunta que surge de inmediato, como formula Sennett, es la siguiente: “¿Cómo puede un ser humano desarrollar un relato de su identidad e historia vital en una sociedad compuesta de episodios y fragmentos?"14.

En el contexto de la cultura de consumo, el diseño, la publicidad, los mass media o la moda devienen agentes cruciales como mediadores y proveedores de los materiales a partir de los que llevar a cabo una "autoconstitución" o "autoconstrucción" de la identidad. Como afirma Kellner:

Radio, television, film, and the other products of the culture industries provide the models of what it means to be male or female, successful or a failure, powerful or powerless. Media culture also provides the materials out of which many people construct their sense of class, of ethnicity

\footnotetext{
${ }^{10}$ Kellner, D. "Popular culture and the construction of postmodern identities", en Lash, S. and Friedman, J. (ed.) (1992): Modernity and Identity, Oxford, Blackwell, 141-177 (141).

11 Hall, S. (1996) "Introduction: Who needs "identity"?", en Hall, S and Du GaY, P. (eds.): Questions of Identity, Thousand Oaks, Sage, 1-17 (4).

12 Bauman, Z. (2001): La posmodernidad y sus desencantos, Madrid, Akal, 35.

13 Lipovetsky, G. (2002): La era del vacio, Barcelona, Anagrama, 58.

14 Sennet, R. (2000): La corrosión del carácter, Barcelona, Anagrama, 25.
} 
and race, of nationality, of sexuality, of 'us' and 'them'. Media culture helps shape the prevalent view of the world and deepest values: it defines what is considered good or bad, positive or negative, moral or evil. Media stories and images provide the symbols, myths, and resources which help constitute a common culture for the majority of individuals in many parts of the world today. Media culture provides the materials to create identities whereby individuals insert themselves into contemporary techno-capitalist societies and which is producing a new form of global culture ${ }^{15}$.

En este sentido, los valores y estilos de vida son cada vez más importantes a la hora de estudiar el comportamiento del consumidor, puesto que en nuestro presente nos encontramos con una identidad construida principalmente a partir de ellos ${ }^{16}$. Y es a través de la creación de espacios, imágenes, objetos u otros artefactos, como publicistas y diseñadores - a los que podríamos añadir otros que conforman los denominados mediadores culturales- se relacionan dialécticamente con el entorno social y cultural, conformando valores, intereses, expectativas y estilos de vida que representan el entorno donde habitamos a la vez que constituyen el marco, las condiciones de posibilidad y los recursos simbólicos y discursivos para la construcción narrativa de identidades, es decir, como factor expresivo y productor de significado e identidad por cuanto el consumo, concebido de modo creciente como un fenómeno más "activo" y "participativo" en el que el consumidor deviene el protagonista y aparece íntimamente relacionado con la construcción de la identidad.

De este modo, es lugar común convenir en señalar que la sociedad de consumo ha adoptado un rol central a la hora de estructurar y compartir significados sociales en la construcción, mediación y expresión de identidades de modo que, como afirma Bocock, es generalmente aceptado que "el consumo es tan fundamental para la gente porque forma parte del proceso de creación y preservación de identidades"17.

Si bien el recorrido realizado hasta ahora nos permite subrayar que la cuestión de la identidad es extremadamente amplia, pluridisciplinar y omnipresente en los debates actuales, interesa en estas páginas, más allá de esta constatación, centrar la atención en cómo la publicidad de la significación ${ }^{18}$ constituye un artefacto cultural privilegiado a la hora de considerar la cuestión de la identidad en nuestra sociedad de consumo y, más específicamente, en la actual virtualización del capitalismo tardio ${ }^{19}$.

${ }^{15}$ Kellner, D. (1995): Media Culture: Cultural Studies, Identity Politics Between the Modern and the Postmodern, London, Routledge, 1.

${ }^{16}$ Chaney, D. (2003): Estilos de vida, Madrid, Talasa. También Alonso, L. E. (2005): La era del consumo, Madrid, s. XXI.

17 Bocock, R. (1995): El consumo, Madrid, Talasa, 165.

${ }_{18}$ Antonio Caro distingue entre una publicidad referencial y una publicidad de la significación. La primera sería la propia del capitalismo de producción decimonónico, mientras que la segunda se corresponde con el capitalismo del signo/mercancía. Esta clasificación representa un desarrollo de la planteada inicialmente por Jesús Ibáñez, que distinguía entre una publicidad estructural y una publicidad referencial. Ver especialmente, CARO, A. (1994): La publicidad que vivimos, Madrid, Celeste Eresma, 119-123, CARO, A. (1993): La publicidad de la significación (marco, concepto y taxonomía), Madrid, Servicio de Publicaciones de la Universidad Complutense de Madrid, 92-96, así como IBAÑEz, J. (1994): Por una sociología de la vida cotidiana, Madrid, Siglo XXI, 233-234.

19 Las nociones de virtualización del capitalismo tardio, renovada producción semiótica, 
En este contexto, como se tratará de mostrar, es posible considerar la cuestión de la identidad en el marco de una publicidad actual centrada en vehicular la actividad proyectiva del sujeto consumidor, con el objetivo de que éste devenga partner de la marca mediante la adhesión experiencial a su mundo imaginario.

La publicidad de la significación trata, por tanto, de que el imaginario de marca aparezca idóneo al sujeto consumidor como factor expresivo por medio de la cual representarse de forma significativa, al poner a disposición de los consumidores una multiplicidad de elementos para que aquél lleve a cabo una actividad de construcción identitaria. Así, si dicho imaginario produce significado para el sujeto consumidor gracias a la representación mediada por su identificación con la marca, la identidad del sujeto consumidor, por tanto, puede construirse narrativamente mediante la experiencia de consumo.

Dicho de otro modo, las herramientas utilizadas por la publicidad de la significación constituyen el "lugar" donde se produce una doble construcción identitaria: mientras que, por una parte, la elaboración de una imagen contenedora de un imaginario de marca persigue dotar a la organización de unos rasgos identitarios supuestamente inherentes a la misma, a su vez, por otra parte, éstos adquieren una importancia decisiva para el sujeto consumidor como factor expresivo y productor de significado e identidad. $\mathrm{Y}$ es precisamente mediante dicha imagen de marca como se realiza la capacidad connotativa tanto de la marca como de sus productos, estableciendo una asociación con unos determinados valores y estilos de vida puesto que, en tanto sistemas simbólicos, consisten en una representación concreta de valores y deseos.

Llegados a este punto, sin embargo, habrá que indagar -lo que es sin duda la cuestión central de estas páginas- cuáles son las características de una actividad proyectiva que lleva a cabo el partner de la marca cuando, más allá de una mera identificación como operación mimética y mediante el uso de la imaginación, tiene lugar la adhesión experiencial al imaginario de marca.

\section{Modos de comprensión de la subjetividad y dimensión simbólica del consumo}

La ya muy traída crisis de la subjetividad y de su fundamento ontológico advierte del carácter constructivo, en la publicidad de la significación, tanto de la identidad del consumidor como de la marca. Dicha crisis ni apareció espontáneamente ni surgió de

actividad proyectiva, partner, así como adhesión experiencial, se hallan inicialmente desarrolladas en VidAl Auladell, F. (2011): "La producción semiótica ante la significatización de la economía (O ¿cómo lograr una publicidad efectiva en la era del capitalismo virtual?)”, Pensar la publicidad. Revista Internacional de Investigaciones Publicitarias, Madrid y Valladolid, Universidad Complutense de Madrid y Universidad de Valladolid, vol. 5, $\mathrm{n}^{\mathrm{o}} 1$, 2011, 75-97. Ahí se interpreta el frecuente uso de elementos emocionales y experienciales en la actividad publicitaria actual en el contexto de la evolución producida en el seno de la denominada publicidad de la significación que viene dando lugar a una renovada producción semiótica de la marca que se halla caracterizada, más pormenorizadamente, en VidAL AulADELL, F.(2012): "La inflación de lo emocional en la actividad publicitaria. ¿Constituye un cambio de paradigma?", Pensar la publicidad. Revista Internacional de Investigaciones Publicitarias, Madrid y Valladolid, Universidad Complutense de Madrid y Universidad de Valladolid, vol. 6, $\mathrm{n}^{\mathrm{o}} 2,173-197$. 
modo aislado sin conexión con la realidad circundante sino que, por el contrario, es posible observar como los modos de comprensión de la subjetividad son siempre fruto de un entorno socioeconómico y cultural con el que, a su vez, se retroalimenta. Se debe, por tanto, a transformaciones profundas de las condiciones de existencia que tienen que ver con la técnica moderna y con la racionalización del mundo y, más concretamente, con el desarrollo del sistema económico. De este modo, según Hardt y Negri, "el advenimiento de una nueva subjetividad había anticipado la reestructuración de la producción, del fordismo al posfordismo, de la modernización a la posmodernización"20.

Como ya se ha señalado, en los últimos desarrollos de la publicidad de la significación, acaecidos en el contexto de la virtualización del capitalismo tardio, que ha dado lugar a una renovada producción semiótica de la marca en la que el consumo de elementos emocionales $y / o$ experienciales ha ido adquiriendo un creciente protagonismo una publicidad emocional que constituye un artefacto cultural privilegiado a la hora de considerar la cuestión de la identidad concebida como proyecto autoconstituyente y en perpetua construcción. Así, la publicidad más reciente proporciona los elementos idóneos para la constitución de la identidad mediante un consumo basado en la experiencia y en la que el sujeto consumidor tiene como misión principal llevar a cabo una autoconstrucción identitaria lo que va, por tanto, más allá de ser una mera identificación.

En un contexto en el que el consumo no puede dejar de analizarse sin dejar de observar su dimensión simbólica y que, además, puede ser concebido como un consumo existencial, se abren importantes interrogantes que conciernen a la cuestión de la identidad. Como afirma Rifkin:

De lo que no queda duda es que en una economía inmersa en la venta de mercancías culturales y experiencias de vida, la fragmentación de cada yo en múltiples personalidades aumentará el número de mercados potenciales y retroalimentará el consumo existencial. Si la vida de cada uno es un mercado en potencia para la producción, cuantas más personalidades se tengan, más mercados se podrán explotar. El nuevo individualismo no está asociado a metarrelatos sino a un caleidoscopio de sensaciones que nutre preferencias de un consumo existencial ${ }^{21}$.

${ }^{20}$ Hardt, M. Y Negri, T. (2002): Imperio, Barcelona, Paidós, 256. Por su parte, afirma Gianni Vattimo: “[...] tal desfondamiento en la línea ontológica de una ontología nihilista -rasgo que aproxima a Nietzsche y Heidegger- tiene lugar [...] no a consecuencia de un puro juego de conceptos, sino en relación con transformaciones profundas de las condiciones de existencia, que tienen que ver con la técnica moderna y con su racionalización del mundo [...] Destino de la subjetividad, descubierta en su carencia de fundamento, y disolución nihilista del ser, se enlazan entre sí y con la historia de la racionalización tecnológico-científica del mundo. Es la organización técnica del mundo la que torna obsoletos ya sea el ser como fundamento, ya sea a la subjetividad como estructura jerárquica dominada por la autoconciencia" VATTIMO, G. (2001): Ética de la interpretación, Barcelona, Paidós, 135.

${ }^{21}$ Montamat, D. (2005): La economía del consumo posmoderno, Buenos Aires, Ed. Ciudad Argentina, 292. 
Para este autor, la sociedad moderna se caracteriza por su consumo instrumental, de modo que sigue las premisas del utilitarismo que fundamentan la adopción de decisiones racionales tomadas ante la disyuntiva de consumo presente o ahorro. Según afirma, el patrón de consumo moderno evolucionó, en los s. XIX y XX, desde los albores del capitalismo hasta el presente. De este modo, de la ética protestante se pasó al proyecto de autorrealización personal" ${ }^{22}$ y a lo que Eva Illouz denomina un "estilo emocional terapéutico" 23 en el que, de la mano del marketing y la publicidad, el consumo potenció los caracteres identitarios. Las necesidades de consumo fueron evolucionando de una escasez real a una escasez fabricada, con lo que devino consumo de uso, intercambio e identidad, pero sin abandonar su condición accesoria a un proyecto de realización personal. Nos encontramos, en la actualidad, con un consumo para "ser" caracterizado por su carácter adictivo y obligatorio ya desde la infancia ${ }^{24}$ y que constituye un mercado potencial aparentemente inagotable.

En este contexto, la publicidad proporciona modelos que orientan al consumidor, en su vida cotidiana, hacia el desarrollo de una auto-imagen en base a sus posesiones materiales y, principalmente, experiencias de consumo. Sin embargo, como observa Robert S. Dunn, una segunda forma que puede adoptar el consumismo es cuando se dirige hacia lo que denomina self-commodification, en el sentido de que "commodities set the terms under which we think about and construct our identities"25.

\section{El partner de la marca como efecto de una apropiación activa}

Desde la perspectiva del branding, "una marca debe ser una combinación de atractivos físicos, lógicos y emocionales que se complementen"26, "la marca debe enamorar a los consumidores, al tiempo que inspira y participa de sus emociones más

\footnotetext{
${ }^{22}$ En palabras de Stuart Ewen: "en la comercialización del estilo, en sus imágenes, apariencias y aromas, el sueño de la identidad desfila para el juicio de nuestros ojos. No sólo es un sueño de identidad pública, sino que además sondea los bienes de la identidad interior. El estilo, en sus imágenes y objetos, ofrece una tipología provocativa de las necesidades, una política simbólica de la trascendencia. En este sentido, proporciona a la gente un medio poderoso de expresión" (Ewen, S. (1991): Todas las imágenes del consumo, México, Grijalbo, 130).

${ }^{23}$ De acuerdo con Eva Illouz, "el estilo emocional terapéutico emergió en el período relativamente breve que medió entre la Primera y la Segunda Guerra Mundial, y se solidificó y fue puesto al alcance de un público amplio luego de los años sesenta. Sin duda, este estilo hacía uso de los residuos de nociones decimonónicas del yo, pero también presentaba un nuevo léxico para conceptualizar y discutir las emociones y el yo en la esfera de la vida corriente, y también nuevos modos de manejar la vida emocional" (Illouz, E. (2010): La salvación del alma moderna. Terapia, emociones y la cultura de la autoayuda, Madrid, Katz, 29). Lo que dio lugar a nuevos modelos emocionales, expresados y construidos mediante la importante industria de libros de autoayuda (Mc Gee, M. (2005): Self-Help, Inc, New York, Oxford University Press), talk shows televisivos, películas, novelas, series de televisión y, por supuesto, publicidad, que proporcionan narrativas de identidad, es decir, modos de representar al yo.

${ }_{24}^{24}$ Quart, A. (2003): Branded. The Buying and Selling of Teenagers, New York, Basic Books.

25 Dunn, R. S. (2008): Identifying Consumption. Subjects and Objects in Consumer Society, Philadelphia, Temple University Press, 180.

${ }^{26}$ Arnold, D. (1992): Cómo gestionar una marca, Barcelona, Parramón, 38.
} 
profundas" ${ }^{27}$. Se persigue, en definitiva, una vinculación emocional del consumidor con la marca.

La publicidad, por su parte, "necesita emocionarle [al consumidor], crearle sentimientos, hacerle sentir, divertirle, enamorarle y sólo así será eficaz, porque los aspectos emocionales son los que nos impulsan a la acción"28. De este modo, la estrategia publicitaria debe dirigirse hacia establecer un vínculo "afectivo" entre la marca y el consumidor ${ }^{29}$.

Sin embargo, aparece rápidamente un interrogante: ¿en qué consiste esta vinculación emocional del consumidor a la marca que consiste, al fin y al cabo, en lo que podríamos denominar adhesión experiencial al imaginario de marca?

La publicidad actual no alcanza únicamente la construcción de imaginarios de marca con el objetivo de dotarles de una cierta entidad, de modo que trate de dotar a la corporación y a las marcas de una identidad sacando a la luz unos rasgos que son supuestamente inherentes a la misma y que se representan en multitud de distintos soportes (ya sea la imagen visual corporativa u otras formas de comunicación, el diseño de producto y de espacios, ... ). Al contrario, nos encontramos un nuevo escenario que no solo requiere cada vez más la participación activa y cómplice del sujeto consumidor mediante las herramientas de la Web 2.0 sino que, además, el consumidor se halla compelido al consumo por medio de una concepción esencialista de sí mismo y según la cual el consumo es una forma de aproximarse a su yo más auténtico. El consumidor, desde esta perspectiva, construye -o más bien persigue dar con- su propia y original identidad mediante múltiples herramientas tecnológicas así como con los recursos simbólicos en los que participa y de los que se apropia narrativamente.

De este modo, a través de sus prácticas siempre renovadas, los nuevos desarrollos de la publicidad de la significación persiguen llevar a cabo la creación de múltiples identidades -ya sea la de la propia corporación ya sea la de los consumidores-mediante la plasmación de imaginarios en espacios, imágenes, objetos u otros artefactos que conforman el entorno, el marco de posibilidades y los recursos simbólicos y discursivos para la construcción activa de ambas identidades.

Se trata de que, a partir del encuentro activo entre consumidor y corporación, se produzca un descubrirse narrativo del propio yo por medio del consumo.

En la actualidad, el aspecto central lo constituye el hecho de que la autoderminación del yo como proyecto consiste no tanto en un autodescubrimiento sino en una autodefinición y, en este sentido, el individuo se concibe como un múltiple yo a construir

${ }^{27}$ LÓPez VÁzquez, B. (2007): Publicidad emocional. Estrategias creativas. Madrid, ESIC, 38.

${ }^{28}$ Martín Requero, M. I. (2006): “Creativos publicitarios, creadores de sensaciones", en Alvarado López, M. y Martín Requero, M. I. (Coords.), Publicidad y cultura, Sevilla, Comunicación Social, 94 - 128 (126).

${ }^{29}$ Roberts, K. (2006): Lovemarks. El futuro más allá de las marcas, Barcelona, Empresa Activa. 
en cuya tarea adquiere un importante protagonismo la noción de autenticidad ${ }^{30}$, que aparece asimismo reflejada/construida en la actividad publicitaria ${ }^{31}$.

La identidad corporativa, en tanto sistema simbólico, consiste en una representación concreta de valores y deseos que aparece idónea al sujeto consumidor como factor expresivo por medio del cual representarse de forma significativa. Así, mediante todas las formas utilizadas por la corporación para representar su identidad corporativa, aquélla trata de establecer una asociación con su propia identidad y unos valores y estilos de vida que deben ser apropiados - para que sea realmente una apropiación significativa- de forma activa por parte del consumidor. El partner de la marca "realiza" en cierto modo la identidad de la corporación. Se produce, con ello, una representación mediada por la identificación -en una doble constitución existencial simultánea de ambas identidades - entre compañía y consumidor.

Sin embargo, si bien empezábamos esta sección preguntándonos ¿en qué consiste la vinculación emocional que podríamos denominar adhesión experiencial al imaginario de marca y por la cual el consumidor deviene partner de la misma?, quedaría pendiente de dilucidar, a continuación, el interrogante que será objeto de la siguiente sección: ¿cómo es posible que una emoción dé lugar a una adhesión experiencial?.

\section{La imaginación, entre la actividad proyectiva y la adhesión experiencial}

Una vez constatada la importancia y la centralidad de emociones y experiencias en el ámbito del consumo, cabe dilucidar el importante papel de la imaginación ya que, de acuerdo con Eva Illouz, emociones e imaginación se hallan íntimamente relacionadas:

[...] from the end of the 19th century, consumption was associated with the excitation of the imagination: department stores, advertising, movies, billboard posters, window displays, women's magazines, sale catalogues -all of these presented a world of goods that gained cultural power in virtue of its association with glamorous figures and the core symbols of consumer society. The efficiency of these symbolic representations of goods lay primarily in their ability to proper the subject into a realm of possibilities entertained through the exercise of imagination ${ }^{32}$.

Así, las emociones no son menos el resultado de la imaginación que de relaciones sociales concretas. Siguiendo a Eva Illouz:

${ }^{30}$ Como señala Grant McCraken, "Modernist creatures sought authenticity with the conviction that they were both free and obliged to search out an essential self hidden beneath the falsehoods of status transformation, bourgeois convention, and received wisdom. The postmodern self appears to have lost confidence in this scheme. These days, it is rare to hear people, except perhaps in radiant circles, speak, somewhat paradoxically, of a pursuit of several authentic selves. Still more unexpectedly, they will identify the "authentic" self as one of the many selves they whish to claim for themselves" (MCCRAKEN, G. (2008): Transformations: Identity Construction in Contemporary Culture, Bloomington, Indiana University Press, 301).

${ }^{31}$ Así, "advertising's obsession with authenticity is driven by a basic cultural contradiction of corporate capitalism. Signs of authenticity in ads reflect a social world in which concerns about the self, identity, and personhood have become paramount" (GoLDMAN, R. and PAPSON, S. (1996): Sign Wars. The Cluttered Landscape of Advertising, New York, The Gilford Press, 141).

${ }^{32}$ ILlouz, E. (2009): "Emotions, Imagination and Consumption: A new research agenda", Journal of Consumer Cultura, 9, London, SAGE, 377 - 413 (397 - 398). 
[...] much of the emotional power of the cultural consumption resides in the fact that emotions, while being real, are experienced on the imaginary mode. This means that consumer emotions need not be the result of concrete social relationships, but rather that they often are the result of consumers' interactions with a realm of signs and images ${ }^{33}$.

Lo que se consume es, en definitiva, el imaginario de marca, la forma imaginaria que proporciona los elementos para que el sujeto consumidor elabore dichas emociones y experiencias. Así, a diferencia de lo que podría parecer, las emociones no son unos contenidos dados al sujeto que las experimenta pasivamente, sino que, al contrario, éste lleva a cabo una actividad imaginativa que convierte la experiencia sea realmente significativa. De hecho, la adhesión al imaginario de marca, el devenir partner de la marca, tiene lugar de acuerdo al carácter proteico ${ }^{34}$ y existencial que actualmente presenta la identidad, tal y como se ha puesto de relieve en la secciones anteriores.

Así, el individuo es incitado a que tome parte activa en la producción semiótica de la marca y, por ello, es el candidato por antonomasia a la adhesión experiencial a su imaginario, cuyo carácter existencial se viene poniendo de relieve. De algún modo, como afirma Bauman:

En la sociedad de consumidores nadie puede convertirse en sujeto sin antes convertirse en producto, y nadie puede preservar su carácter de sujeto si no se ocupa de resucitar. Revivir y realimentar a perpetuidad en sí mismo las cualidades y habilidades que se exigen en todo producto de consumo. La "subjetividad" del "sujeto" [...] está abocada a la interminable tarea de ser y seguir siendo un artículo vendible ${ }^{35}$.

Sin embargo, tratando de ir más allá de la constatación de Bauman, es posible afirmar que dicha adhesión experiencial se produce por medio de una actividad proyectiva basada en la imaginación y llevada a cabo por parte del consumidor en la tarea de tratar de construir su propia identidad. Así, sucede que mientras la adhesión experiencial se basa en la conexión emocional, para que se produzca una actividad proyectiva cuya pieza clave es la imaginación. Y se podría situar dicha adhesión experiencial, además, en un punto nodal tanto del valor de la marca como de la efectividad de la actividad publicitaria.

Persiste, sin embargo, llegados a este punto, la misma pregunta: ¿cómo se relacionan, más concretamente, las emociones con el consumo mediante la imaginación? ${ }^{36}$. Como

33 Ibidem, 397.

34 Lifton, R. J. (1993): The Protean Self, Basic Books, New York.

35 Bauman, Z. (2007): Vidas de consumo, México, Fondo de Cultura Económica, 25-26.

${ }^{36}$ Cuestión por otra parte, que según Eva Illouz, continúa sin ser clarificada. Así, afirma: “As Colin Campbell has suggested, consumption is driven by dreams and fantasies that connect the individual to the question of who he/she is. In his seminal The Romantic Ethic and the Spirit of Consumerism, Colin Campbell has argued that consumer culture has capitalized on the very losses generated by accelerated production, most notably what we may broadly call 'losses in meaning' (Campbell, 1987). In response, consumer culture has put at its centre stage the 'romantic self", a self full of feeling and longing for authenticity [...] Yet, he does not specify the ways in which imagination and emotions constitute each other to form the consumer self. The two 
hemos visto hasta ahora, la actividad publicitaria trata de conseguir que el consumidor devenga partner de la marca mediante su participación en la experiencia de la marca. Ello se produce en un contexto en el que el acto de consumo se encuentra ahora expandido a otros ámbitos y actividades que no sólo ofrecen información al consumidor, sino que también promueven su participación en eventos a la vez que representan algo más que un "autodescubrimiento" o un reconocimiento que lleva a cabo el consumidor imaginariamente mediante los contenidos imaginarios de la marca.

Así, se propone dar un paso más en la dirección apuntada por Colin Campbell en el sentido de que -si bien éste apunta al consumo como un autodescubrimiento, de modo que es completamente útil su concepción ontológica del consumo- cabe derivar, prolongando sus propuestas, el carácter constructivo de la identidad del sujeto consumidor. Según Campell, no se trata únicamente de que la identidad derive del producto o servicio consumido sino que mediante el consumo hallamos nuestra verdadera identidad ${ }^{37}$. Dicho de otro modo, los consumidores no estarían tanto "comprando" su identidad a través de la adquisición de determinados bienes y servicios como más bien "descubriendo" su identidad a través de la exposición a una amplia gama de productos y servicios. Así, afirma:

[...] consumption, and more especially perhaps shopping, could be seen as a process through which individuals resolve the "problem" of personal identity. That is they "discover who they are" by monitoring their responses to various products and services and therefore establish their distinctive tastes or desires ${ }^{38}$

La imaginación es importante para comprender el modo como la cultura de consumo produce emociones, puesto que es un modo o capacidad de hacer presente lo ausente mediante emociones, de sustituir el objeto real por una experiencia mediante sensaciones próximas a lo que sería en la vida real. La imaginación, en definitiva, es una facultad creativa de la mente:

$[\ldots .$.$] consumer culture thrives on emotions that do not necessarily have referent in reality: nostalgia,$ confidence, envy or anxiety might be provoked in reference to real persons but may very well also occur, as we say, "in one's head". I may know that this toothpaste will not make me joyous or that particular

concepts of imagination and emotions - central to his argument- have remained undertheorized and the exact nature of their relationship left undiscussed" ILLouz, E. "Emotions, Imagination and Consumption ... ", 398-399).

${ }^{37}$ Identidad que se basa, como se ha observado, en un consumo existencial en el que el consumidor adquiere, no tan cómodamente como pudiera parecer, el máximo protagonismo. Así, advierte Guillaume Erner para la moda: "La necesidad de moda se inscribe entre estos dos polos: la voluntad de ser uno mismo y el deseo de relacionarse con el otro [...]. La patología del vínculo es una consecuencia de la incapacidad del individuo contemporáneo de saber quien es. A partir de ahora debe encontrar su lugar sin la ayuda de ninguna tradición. La moda puede intentar asumir este papel integrador ya que permite al individuo posicionarse oponiéndose, pertenecer y distinguirse. Pero la simple operación que consiste en construirse por identificación es más problemática que antes. ¿Cuáles son nuestros modelos?” (ErNer, G. (2005): Víctimas de la moda, Barcelona, Gustavo Gili, 193 - 194.

${ }^{38}$ CAmpbell, C. (2004): "I Shop therefore I Know that I Am: The Metaphysical Basis of Modern Consumerism", en Eкström, K.м. Y Brembeck, H. (ed.), Elusive Consumption, Berg, New York, 27-44, (35). 
brand or car does not "really" make me more aggressive and competitive, yet these commodity-signs and commodity-narratives based on "unasserted beliefs" do generate types of emotions, similar to the emotions we may feel when reading a novel in "real life" 39 .

Sin embargo, a partir de ahí, habría que plantearse nuevamente: ¿cómo se generan las emociones en el consumidor? O, más precisamente y utilizando la terminología que se ha ido dilucidando en estas páginas: ¿cómo emociones y experiencias promueven una actividad proyectiva del consumidor que da lugar a la adhesión experiencial, a que éste devenga partner de la marca?.

Para tratar de responder a estas cuestiones habría que tratar de relacionar la ontología con la intencionalidad de la conciencia, lo que nos sitúa en el punto de partida sugerido por Hackley y Tiwsakul cuando afirman que "there has been a relative lack of studies which focused on how entertainment marketing techniques interpolate the consumer's phenomenologically experienced world" ${ }^{40}$. Por ello, proponen:

We suggest, then, that understanding of the emerging area of entertainment marketing can be enhanced by recourse to the existential/phenomenological research traditions. These approaches are needed in order to capture the distinctive quality of entertainment marketing, namely, that is blurs the cognitive separation between entertainment and persuasive promotion.

We feel that these qualitative traditions of research can potentially provide fertile new directions for the area because of their ability to capture the integrity of consumer experience in holistic, contextually flexible and theoretically novel ways ${ }^{41}$.

Sin embargo, se trata de un punto de partida sugerido pero no desarrollado, de modo que es interesante tratar de avanzar un paso más para ahondar en el papel que desempeña la imaginación en la adhesión experiencial al imaginario de marca.

${ }^{39}$ ILlouZ, Eva, "Emotions, Imagination and Consumption ... “ , 400. "Unasserted beliefs are beliefs about actions and characters that we know do not exist. Yet these "unasserted beliefs" -imagination- provoke real emotions" (Ibídem, 400).

40 Hackley, C. and Tiwsakul, R.A. (2006): "Entertainment marketing and experiential consumption", Journal of marketing communications, 12 (1), 63-75, 10, http://dro.dur. ac.uk/8555/1/8555.pdf el 17-12-2012. Web visitada el 17-12-2012.

${ }^{41}$ Cfr. Hackley, C. and Tiwsakul, R.A. Ibídem, 8. Así, señalan, más concretamente: "Existential phenomenology offers some useful concepts for understanding the experience of consumers in engagement with entertainment marketing. Put simply, such research would seek to understand how consumers' draw meaning from (and project meaning onto) entertainment marketing incidents and how they then integrate these meanings into their lived experience to reinforce or construct their self concept. Existential phenomenology in consumer research (Thompson et al, 1989) is influenced by phenomenological philosophy and its adaptation to social research (Gurswitch, 1974). Existentialism (Sartre, 1943, 1946) and humanism (Hirschman, 1986) have also proved highly influential. Phenomenological philosophy sought to apprehend direct experience unmediated by intellectual structures. Later adaptations of phenomenology drew on humanistic principles to emphasise the human search for authenticity and its expression through reflective, personal, subjective experience" HaCKLEY, C. and TiwsaKul, R.A. Ibídem, 6. 
En La trascendencia del ego, Sartre realizó un análisis de fenomenología de la conciencia a partir de la noción husserliana de intencionalidad. Según ésta, toda conciencia es conciencia de algo que no es ella misma. Es un proyectarse fuera de sí misma hacia algo exterior. Es conciencia de ser conciencia de un objeto trascendente a las conciencias que lo captan. Sartre criticó a Husserl haber hecho del yo, igual que Descartes y Kant, una conciencia trascendental mientras que consideró, por el contrario, que "el Ego no está ni formalmente ni materialmente en la conciencia: está fuera, en el mundo; es un ser del mundo como el Ego del otro" 42.

El sujeto, así considerado, quedó desalojado de la conciencia, careciendo de presencia formal o material en la misma y no actuando ni como principio de unificación de vivencias ni como centro de deseos y actos, sino siendo únicamente un objeto aprehendido y constituido por una conciencia reflexiva, un puro dinamismo intencional vacío de contenido.

La fenomenología de la conciencia iniciada en La trascendencia del ego fue prolongada con las descripciones sobre la imaginación y las emociones en $L a$ imaginación y Lo imaginario. La imagen, según Sartre, es también imagen de alguna cosa, de modo que nos encontramos, pues, ante una relación intencional de una cierta conciencia a un cierto objeto, ya que "la imagen es, entre los datos sensibles, lo que no puede pasar a lo objetivo. La imagen es la subjetividad" ${ }^{43}$. De modo que la imagen deja de ser un contenido psíquico, no encontrándose ya dentro de la conciencia, sino dentro de la conciencia de alguna cosa en imagen. Las imágenes no son, por tanto, recibidas en la conciencia, sino que la conciencia que imagina es, de modo primario, conciencia intencional.

Siguiendo a Sartre, cabe señalar que la imagen no se encuentra, por tanto, en la conciencia y, además, el objeto de la imagen tampoco está en la imagen. La conciencia, por su parte, no es un lugar poblado de pequeños simulacros, que serían las imágenes, puesto que la conciencia nunca precede al objeto. Por el contrario, la imagen presenta el objeto como ausente y, por tanto, irreal, de modo que "se puede decir en este sentido que la imagen encierra una determinada nada" ${ }^{44}$. Y es precisamente necesario para que la conciencia pueda imaginar que tenga la posibilidad de proponer una tesis de irrealidad, de poder formar y proponer objetos con un cierto carácter de nada en relación con la totalidad de lo real. Así, afirma Sartre que "para imaginar, la conciencia tiene que estar libre en relación a toda realidad particular, y esta libertad se tiene que poder definir como un estar-en-el-mundo que es a la vez constitución y anonadamiento de este mundo" ${ }^{45}$. De este modo, la imaginación es la condición necesaria de la libertad del hombre, ya que éste imagina por qué es libre.

\footnotetext{
42 SARTRe J.P. (1968): La trascendencia del ego, Calden, Argentina,11.

43 Sartre J.P. (1978): La imaginación, Edhasa, Barcelona, 84.

44 SArtre J.P. (1964): Lo imaginario, Losada, Buenos Aires, 25

45 Ibídem, 229.
} 
Esta función irrealizante de la conciencia se encuentra también en Bosquejo de una teoría de las emociones, donde Sartre caracteriza la conciencia como ser en el mundo y la emoción como un modo de esta conciencia opuesta al comportamiento de este mundo. La emoción se interpreta como una sustitución, de un modo mágico, de una determinada configuración real de un mundo repleto de dificultades por otra estructura de la realidad considerada más soportable o satisfactoria.

La emoción es, pues, un modo de existencia de la conciencia, una de las modalidades en que la misma comprende su ser en el mundo. Las emociones "remiten a lo que significa. Y lo que significa es la totalidad de las relaciones de la realidad-humana con el mundo" ${ }^{46}$. Son una forma de estar en el mundo. En la emoción encontramos una realidad que hemos imaginado o proyectado nosotros mismos. Las emociones, por tanto, son formas organizadas de la existencia humana de modo que son significativas, es decir, indican la realidad humana en su relación con el mundo y expresan la totalidad del proyecto humano.

Todo ello nos lleva a proponer que el modo como Sartre concibe el papel y los caracteres de la imaginación, nos proporciona una mayor comprensión de su función ontológica que puede contribuir a dilucidar el carácter constructivo-identitario del consumo. Así, si las emociones no tienen un referente real sino que, en todo caso, es la imaginación del consumidor la que genera las emociones con las que se construye a sí mismo, ello nos permite comprender mejor cómo funciona la que se ha denominado adhesión experiencial.

\section{Conclusión}

En las páginas anteriores se ha tratado de dilucidar en qué consiste y cuáles son los caracteres constitutivos, definidores y singulares, de una adhesión experiencial del consumidor a la marca que no consiste en una "mera" identificación sino que requiere un componente activo y constructivo que se ha denominado actividad proyectiva.

Dicha adhesión, que se produce cuando el consumidor deviene partner de la marca y que se concreta en la medida en que éste participa de modo ficcional ${ }^{47}$ en la construcción de su imaginario, se lleva a cabo en la tarea de tratar aquél de construir o, mejor dicho, de reconocer su propia identidad mediante el consumo, lo que es propiciado mediante todo un elenco de novedosas estrategias que caracterizan los más recientes desarrollos de la publicidad de la significación.

De todos modos, si bien todo ello ha conducido a destacar y ahondar en el papel que desempeña la imaginación en la producción de emociones, en la actividad proyectiva del consumidor y en su adhesión experiencial al imaginario de marca, algunas tareas han quedado pendientes.

Así, se han recogido algunas de las aportaciones de la psicología fenomenológica y de la sociología de las emociones que permitirán dar un paso más en la dirección apuntada a la vez que abren la puerta a considerar la posibilidad de desentrañar, cuestión

46 SARTRE J.P. (2005): Bosquejo de una teoría de las emociones, Madrid, Alianza Editorial, 101.

47 Vidal Auladell, F. (2013): "La (co) creación ficcional de la autenticidad vivencial como valor de marca en la Web 2.0: el caso Bench", Klaus, Z., CuencA, J. y Rom, J. (eds.) Breaking the Media Value Chain, Barcelona, Universidad Ramon Llull, 283 - 292. 
que excede por completo el propósito de estas páginas, hasta qué punto si, como señala Eva Illouz, "la publicidad constituye un ámbito privilegiado para el estudio de las utopías" 48 , la actividad publicitaria cuenta, mediante la actividad proyectiva que lleva a la adhesión experiencial del consumidor al imaginario de marca, con un impulso que le sirve de combustible con el que reinventarse constantemente.

\section{Bibliografía}

Alonso, L. E. (2005): La era del consumo, Madrid, s. XXI.

Anderson, B. (1993): Comunidades imaginadas. Reflexiones sobre el origen y la difusión del nacionalismo, México, FCE.

ARnold, D. (1992): Cómo gestionar una marca, Barcelona, Parramón.

Bauman, Z. (2001): La posmodernidad y sus desencantos, Madrid, Akal.

Bauman, Z.(2001): La sociedad individualizada, Cátedra, Madrid.

BAUMAN, Z.(2005): Identidad, Madrid, Losada.

Bauman, Z.(2007): Vidas de consumo, México, Fondo de Cultura Económica.

Bermejo, J. (2008): "El receptor publicitario del siglo XXI en el marco de la interactividad: entre el consumer y el prosumer", en PACHECO RUEDA, Marta. (coord.), La publicidad en el contexto digital, Comunicación Social Ediciones y Publicaciones, Sevilla- Salamanca-Zamora, 49-78.

BLoch, E. (2007): El principio esperanza I, Madrid, Trotta.

Bocock, R. (1995): El consumo, Madrid, Talasa.

CAmpBell, C. (2004): "I Shop therefore I Know that I Am: The Metaphysical Basis of Modern Consumerism", en Екström, K.м. у BREмBeck, H. (ed.), Elusive Consumption, New York Berg, 27-44.

CARo, A. (1994): La publicidad que vivimos, Madrid, Celeste Eresma.

CAro, A. (1993): La publicidad de la significación (marco, concepto y taxonomía), Madrid, Servicio de Publicaciones de la Universidad Complutense de Madrid.

${ }^{48}$ ILLOUZ, E (2009): El consumo de la utopía romántica, Madrid, Katz, 124. En este sentido, Eva Illouz parecería seguir a Fredric Jameson, para quien los textos de la cultura de masas suelen contener momentos utópicos, de modo que sería posible analizar esperanzas y fantasías que son aparecen mezcladas con formas ideológicas: «[...] we will now suggest that anxiety and hope are two faces of the same collective consciousness, so that the works of mass culture, even if their function lies in the legitimation of the existing order -or some worse one- cannot do their job without deflecting in the latter's service the deepest and most fundamental hopes and fantasies of the collectivity, to which they can therefore, no matter in how distorted a fashion, be found to have given voice» JAMESON, F. (1979): «Reification and Utopia in Mass Culture» Social Text, I, 130148 (144). Cuestión que «was not developed by the Frankfurt School» (JAMESON, F. (1977): «Ideology, Narrative Analysis, and Popular Culture», Theory and Society, 4, (4), 543 $-559,(544))$ aunque sí por un autor como Ernst Bloch, especialmente en el primer volúmen de El principio esperanza (BLOCH, E. (2007): El principio esperanza I, Madrid, Trotta), cuestión que ha sido analizada, entre otros, por Douglas Kellner (KELLNER, D. (1997): «Ernst Bloch, Utopia, and Ideolgy Critique», en DANIEL, J. O. and MOYLAN, T. Not Yet. Reconsidering Ernst Bloch, London, Verso, 80 - 95). Ver, asimismo, JAMESON, F. (2009): Arqueologías del futuro. El deseo llamado utopía y otras aproximaciones de ciencia ficción, Madrid, Akal. 
Chaney, D. (2003): Estilos de vida, Madrid, Talasa.

Dunn, R. S. (2008): Identifying Consumption. Subjects and Objects in Consumer Society, Philadelphia, Temple University Press.

Eagleton, T. (1997): Las ilusiones del posmodernismo, Buenos Aires, Paidós.

Eco, U. (2005): Apocalipticos e integrados, Barcelona, Tusquets.

ERNER, G. (2005): Victimas de la moda, Barcelona, Gustavo Gili.

Ewen, S. (1991): Todas las imágenes del consumo, México, Grijalbo.

Goldman, R. and Papson, S. (1996): Sign Wars. The Cluttered Landscape of Advertising, The Gilford Press, New York.

HaCkley, C. and Tiwsakul, R.A. (2006): "Entertainment marketing and experiential consumption.', Journal of marketing communications", 12 (1), 63-75. [Consultado en http://dro.dur.ac.uk/8555/1/8555.pdf el 17-12-2012].

Hall, S. "Introduction: Who needs "identity"?", en Hall, S and Du GaY, P. (eds.): Questions of Identity, Thousand Oaks, Sage, 1996, 1-17.

HARDT, M. Y Negri, T. (2002): Imperio, Barcelona, Paidós.

Hobswam, E. (1996): "Identity politics and the left", New Left Review, n²17, 38-47.

IBAÑEZ, J. (1994): Por una sociología de la vida cotidiana, Siglo XXI, Madrid.

ILlouz, E. (2009): "Emotions, Imagination and Consumption: A new research agenda", Journal of Consumer Cultura, 9, London, SAGE, 377 - 413.

Illouz, E. (2009): El consumo de la utopía romántica, Madrid, Katz.

Illouz, E. (2010): La salvación del alma moderna. Terapia, emociones y la cultura de la autoayuda, Madrid, Katz.

JAMEson, F. (1977): "Ideology, Narrative Analysis, and Popular Culture", Theory and Society, 4, (4), $543-559$.

JAMESON, F. (1979): "Reification and Utopia in Mass Culture" Social Text, I, 130 - 148.

JAMESON, F. (2009): Arqueologías del futuro. El deseo llamado utopía y otras aproximaciones de ciencia ficción, Madrid, Akal.

KelLner, D. (1992): "Popular culture and the construction of postmodern identities", en LASH, S. and Friedman, J. (ed.): Modernity and Identity, Blackwell, Oxford, 141177.

Kellner, D. (1995): Media Culture: Cultural Studies, Identity Politics Between the Modern and the Postmodern, London, Routledge.

Kellner, D. (1997): "Ernst Bloch, Utopia, and Ideolgy Critique", en Daniel, J. O. and Moylan, T. Not Yet. Reconsidering Ernst Bloch, London, Verso, 80 - 95.

Lifton, R. J. (1993): The Protean Self, New York, Basic Books.

LipovetSKy, G. (2002): La era del vacio, Barcelona, Anagrama.

LóPez VÁzquez, B. (2007): Publicidad emocional. Estrategias creativas. Madrid, ESIC.

Martín Requero, M. I. (2006): "Creativos publicitarios, creadores de sensaciones", en Alvarado López, M. Y Martín Requero, M. I. (Coords.), Publicidad y cultura, Comunicación Social, Sevilla, 94 - 128.

MCCRaken, G. (2008): Transformations: Identity Construction in Contemporary Culture, Bloomington, Indiana University Press.

Mcgee, M. (2005): Self-Help, Inc, New York, Oxford University Press.

Montamat, D. G. (2005): La economía del consumo posmoderno, Ed. Ciudad Argentina, Buenos Aires. 
Quart, A. (2003): Branded. The Buying and Selling of Teenagers, New York, Basic Books.

Ricoeur, P. (1996): Si mismo como otro, Madrid, s.XXI.

RoBERTs, K. (2006): Lovemarks. El futuro más allá de las marcas, Barcelona, Empresa Activa.

SARTRE, J. P. (1968): La trascendencia del ego, Argentina, Calden.

SARTRE, J. P (1978): La imaginación, Barcelona, Edhasa.

SARTRE, J. P. (1964): Lo imaginario, Buenos Aires, Losada.

Sartre, J. P. (2005): Bosquejo de una teoría de las emociones, Madrid, Alianza Editorial.

SEnNet, R. (2000): La corrosión del carácter, Barcelona, Anagrama.

Storey, J. (1999): Cultural Consumption and Everyday Life, London, Arnold.

TAYLOR, Ch. (2006): Fuentes del yo, Barcelona, Paidós.

TOFFler, A. (1992): El "shock" del futuro, Barcelona, Plaza\&Janés.

Vattimo, G. (2001): Ética de la interpretación, Paidós, Barcelona.

Vidal Auladell, F. (2011): "La producción semiótica ante la significatización de la economía (O ¿cómo lograr una publicidad efectiva en la era del capitalismo virtual?)", Pensar la publicidad. Revista Internacional de Investigaciones Publicitarias, Madrid y Valladolid, Universidad Complutense de Madrid y Universidad de Valladolid, vol. $5, \mathrm{n}^{\circ} 1,75-97$.

Vidal Auladell, F. (2012): "La inflación de lo emocional en la actividad publicitaria. ¿Constituye un cambio de paradigma?", Pensar la publicidad. Revista Internacional de Investigaciones Publicitarias, Madrid y Valladolid, Universidad Complutense de Madrid y Universidad de Valladolid, vol. 6, n², 173-197.

Vidal Auladell, F. (2013): "La (co) creación ficcional de la autenticidad vivencial como valor de marca en la Web 2.0: el caso Bench", KLaus, Z., Cuenca, J. y Rom, J. (eds.) Breaking the Media Value Chain, Barcelona, Universidad Ramon Llull, $283-292$. 